\title{
Las representaciones sociales del campo de la comunicación
}

\author{
SiLVIA GutírRrez VidRio*
}

En la actualidad como consecuencia de la expansión de las nuevas tecnologías de reproducción simbólica y de los cambios en el orden sociopolítico, hemos presenciado transformaciones permanentes que han afectado no sólo el ordenamiento cultural y político de los países sino también los imaginarios sociales por medio de los cuales las sociedades se representan a sí mismas. Los cambios producen alteraciones en el mundo objetivo pero también modifican las ideas que nos hacemos de él.

Este artículo se ocupa específicamente de los cambios en el campo de la comunicación y la formación de los profesionales de este campo. La problemática que enfrentan las escuelas de comunicación en relación con la proliferación de nuevas escuelas de comunicación, la constante renovación de los planes de estudio, la adaptación de los perfiles diseñados, la saturación del campo de trabajo de los egresados, ha sido ampliamente discutida en foros y publicaciones especializadas pero poco se ha dicho sobre las representaciones que tienen los actuales alumnos sobre el campo de la comunicación y su objeto de estudio.

Considero que el tema es relevante ya que las representaciones sociales que circulan sobre lo que es el campo de la comunicación son importantes tanto para las personas que están involucradas en el diseño curricular de las carreras de comunicación como para la gente que emplea a los egresados y para los jóvenes que desean estudiar dicha carrera.

El propósito de este artículo es dar a conocer los avances preliminares sobre un proyecto de investigación que actualmente estoy desarrollado que tiene como tema precisamente la identificación de

* UAM, Xochimilco,México

'Varios de los Encuentros organizados por el CONEICC se han centrado en la discusión de la problemática de la escuelas de Comunicación. Una publicación en donde se encuentran varios artículos que abordan esta problemática es el No. 62 de la revista Diálogos de la comunicación, julio 2001, Perú. 
las representaciones que tienen los alumnos de la Licenciatura en Comunicación Social de la UAM-X México, sobre el campo y el objeto de la comunicación social ${ }^{2}$.

El objetivo central de esta investigación es indagar ¿cuáles son las representaciones sociales que operan en los imaginarios colectivos del alumnado?. Estas representaciones subyacen; con diverso grado de aceptación o confrontación en los perfiles que las carreras proponen y en las motivaciones que impulsan a ciertos jóvenes a estudiar Comunicación Social. Por lo cual, me he planteado investigar a través de una metodología basada en la propuesta de Grize J. B., Verges, P., et Silem, A. (1987), ¿cuáles son las representaciones que tienen sobre lo que hace y debe hacer un comunicador social?, ¿en qué preconstruidos políticos, sociales, ideológicos se anclan?, ¿cómo es que se han ido construyendo ciertas representaciones sociales sobre el campo?, ¿cómo es que las representaciones dan origen a un punto de vista específico sobre el trabajo del profesional de la comunicación?, ¿qué papel juegan los avances tecnológicos y el proceso de globalización en las representaciones que circulan?

Además, esta investigación pretende mostrar que la propuesta teórico metodológica de las representaciones sociales puede ser de gran utilidad para el análisis de la comunicación social. Este acercamiento teórico no ha sido adoptado por muchos de los investigadores que trabajan en el campo de la comunicación ${ }^{3}$. Una de las razones que se podrían ofrecer como explicación es que al ligar el término representación social con el del imaginario social, es decir, con lo "imaginario", esta asociación inhibe el acceso a las representaciones sociales por considerarlas como imaginarias y, por lo tanto, sin base real. La terminología, desde luego, presenta inconvenientes ya que los términos imaginario e imaginación están fuertemente anclados en nuestra tradición lingüística y tienen, a menudo, connotaciones "negativas". Me interesa mostrar que las representaciones sociales no son simples reflejos de la realidad, sino

${ }^{2}$ Este proyecto es parte de mi tema de investigación que lleva como título "Las representaciones sociales y su aplicación en el campo de la comunicación social".

${ }^{3}$ Una excepción es el trabajo de Claudia Benassini titulado "El imaginario social del comunicador. Una propuesta de acercamiento teórico" en Razón y Palabra, Primera revista electrónica en América Latina especializada en tópicos de la comunicación, febrero-marzo 2002, ITESM. Para analizar la construcción del imaginario sobre la carrera de comunicación Benassini utiliza el concepto de imaginario social. 
que tienen una realidad especiffica que reside en su misma existencia, en su impacto variable sobre las mentalidades y los comportamientos colectivos, en las múltiples funciones que ejercen en la vida social.

Las representaciones sociales son una manera de interpretar y de pensar nuestra realidad cotidiana, una forma de conocimiento del entramado social. También, son la actividad mental desplegada por individuos y grupos a fin de fijar su posición en relación con situaciones, acontecimientos, objetos y comunicaciones que les conciernen.

\section{Las representaciones sociales}

El concepto moderno de representación social tiene su origen en la obra de S. Moscovici El psicoanálisis su imagen y su público (1961). Con su teoría de las representaciones sociales, Moscovici integra en una psicología social las aportaciones de diversas disciplinas, dentro de un contexto europeo de rápida expansión.

A partir de la obra de Serge Moscovici, la noción de representación ha cobrado un lugar fundamental en las ciencias sociales, la psicología cognitiva, la inteligencia artificial y la comunicación social. El término representación social constituye la designación de fenómenos múltiples que se observan y estudian a variados niveles de complejidad, individuales y colectivos, psicológicos y sociales. Además, constituye también una nueva unidad de enfoque fecunda para el análisis de los procesos comunicativos.

Para Moscovici, una representación social es "una modalidad particular de conocimiento cuya función es la elaboración de los comportamientos y la comunicación entre los individuos. Es un corpus organizado de conocimientos y una de las actividades psíquicas gracias a las cuales los hombres hacen inteligible la realidad física y social, se integran en un grupo o en una relación cotidiana de intercambios, liberan los poderes de su imaginación" (1979: 17-18).

En tanto que fenómenos, las representaciones sociales se presentan bajo formas variadas, más o menos complejas. Imágenes que condensan un conjunto de significados, sistemas de referencia que nos permiten interpretar lo que nos sucede, e incluso, dar un sentido a lo inesperado; categorías que sirven para clasificar las circunstancias, los fenómenos y a los individuos con quienes tenemos algo que ver; teorías que permiten establecer hechos sobre ellos. $Y$ a menudo cuando 
se les comprende dentro de la realidad concreta de nuestra vida social, las representaciones sociales son todo ello junto (Jodelet 1986: 472).

La noción de representación social tiene que ver con la manera como nosotros, sujetos sociales, aprehendemos los acontecimientos de la vida diaria, las características de nuestro medio ambiente, las informaciones que en él circulan, a las personas de nuestro entorno próximo lejano. En pocas palabras, el conocimiento "espontáneo", "ingenuo" que tanto interesa en la actualidad a las ciencias sociales, ése que habitualmente se denomina conocimiento de sentido común, o bien pensamiento natural. Este conocimiento se constituye a partir de nuestras experiencias, pero también de las informaciones, conocimientos, y modelos de pensamiento que recibimos y transmitimos a través de la tradición, la educación y la comunicación social. De ahí la importancia de que en el campo de la comunicación se conozca y maneje este acercamiento a los fenómenos sociales y comunicativos.

Las representaciones sociales son una manera de interpretar y de pensar nuestra realidad cotidiana, una forma de conocimiento social. También son la actividad mental desplegada por individuos y grupos a fin de fijar su posición en relación con situaciones, acontecimientos, objetos y comunicaciones que les conciernen. Lo social interviene ahí de varias maneras: a través del contexto concreto en que se sitúan los individuos y los grupos; a través de la comunicación que se establece entre ellos; a través de los marcos de aprehensión que proporciona su bagaje cultural; a través de los códigos, valores e ideologías relacionados con las posiciones y pertenencias sociales específicas (Jodelet 1986: 473).

\section{La mediación comunicativa y las representaciones sociales.}

Dado que esta investigación tiene por objeto de estudio el campo de la comunicación y que como he señalado, la propuesta teórico metodológica de las representaciones sociales es de gran utilidad para estudiar los fenómenos comunicativos, en este apartado resalto la importancia de la mediación comunicativa en la formación de las representaciones.

Las fuentes que emiten sus opiniones y argumentos en los medios masivos tienen un papel importante en la formación de las representaciones sociales. Aunque no son el único factor de origen de 
las representaciones, su influencia se encuentra entre las más importantes y complejas.

De acuerdo con Ibáñez en su plano más general, las fuentes de determinación de las representaciones sociales "se encuentran en el conjunto de condiciones económicas, sociales, históricas que caracterizan a una sociedad determinada y el sistema de creencias y de valores que circulan en su seno" (1994:178). De manera más específica se forman también a partir del conjunto de prácticas que tienen que ver con la comunicación social: "tanto los medios que tienen un alcance general, al estilo de la televisión, como los que se dirigen a categorías sociales específicas, al igual que las revistas de divulgación científica por ejemplo, desempeñan un papel fundamental en la conformación de la visión de la realidad que tienen las personas sometidas a su influencia" (1994:179).

Hay que mencionar que las representaciones sociales se forman después de un tiempo prolongado de tener contacto con la nueva noción, y no son producto de sólo algunas semanas o unos pocos acontecimientos. Sin embargo, su origen y nutriente principal se debe buscar en los medios de comunicación masiva. Según algunos teóricos (Moscovici 1979, Piñuel1987, Ibáñez 1994, Jodelet 1986), son ellos los que imponen los temas que se emplean en las conversaciones cotidianas, que son el lugar donde las representaciones sociales se generan y desarrollan con libertad.

Las discusiones sobre lo que hemos visto la noche anterior en la televisión o de lo que hemos leído en la prensa constituyen una gran parte de nuestras conversaciones cotidianas. Muchos de nosotros dependemos de los medios de comunicación de masas para informarnos ${ }^{4}$ sobre los temas de los que no tenemos una experiencia personal directa - la investigación sobre el genoma humano, por ejemplo. Por lo tanto el análisis de los medios de comunicación de masas es una de las muchas formas posibles de detectar las representaciones sociales que circulan en nuestra sociedad.

Las conversaciones cotidianas, objeto de estudio por excelencia de los investigadores sociales, no sólo denotan influencias de la lengua socializada y las características del emisor, sino que incluyen

${ }^{4}$ Según las estadísticas más recientes en la Encuesta Nacional sobre Cultura Política y Practicas Ciudadanas (ENCUP2003) en México un 76.4\% de la gente se informa por medio de la televisión, un $15 \%$ por la radio y solo un $6 \%$ por la prensa, cf. la página www.gob.mx. 
contenidos y formas pertenecientes a otro tipo de comunicación: la de los medios masivos. Es precisamente la comunicación de masas la que al reflejar, crear y transformar las representaciones sociales, ordena muchos de los contenidos e incluso las conversaciones. Numerosas representaciones son sociales porque son transmitidas por los medios de comunicación (Farr 1986:496). Esto ilustra todo el interés que tiene el análisis de la información que circula a través de los medios de comunicación para el estudio de las representaciones sociales y también el por qué el acercamiento teórico metodológico de las representaciones sociales es de gran utilidad para el estudio de los medios.

Las representaciones sociales que circulan en los discursos, son "vehiculizadas" por las palabras, los mensajes y las imágenes de los medios de comunicación y son cristalizadas en las conductas de los individuos, los grupos y las comunidades. La comunicación juega, en este proceso, un rol fundamental en el intercambio e interacción que concurren a la creación de un universo consensual. De ahí que las representaciones sociales tengan que ser abordadas, a la vez como el proceso y el producto de una actividad de apropiación de la realidad externa a la producción del pensamiento y de la elaboración psicológica y social de esta realidad.

También habría que mencionar que las funciones comunicativas que caracterizan a los Medios de Comunicación Masiva (MCM) se desarrollan en el marco más general de los procesos de mediación social (Cf. Martín Serrano 2001). Toda mediación social se propone proporcionar modelos que sirvan de referencia al grupo, para preservar su cohesión de los efectos disgregadores que tiene el cambio social. Los MCM participan en ese esfuerzo integrador en el que también intervienen otras instancias mediadoras; por ejemplo la familia, la escuela, los iguales. El conjunto de esas mediaciones muestran sus efectos en la existencia de representaciones colectivas.

Los MCM seleccionan determinados acontecimientos para hacerlos públicos. La mediación específicamente comunicativa comienza cuando eligen, en el marco de tales aconteceres públicos, determinados objetos de referencia.

Como señala Piñuel (1987:54) “a diferencia de las representaciones individuales, cuyos productos no siempre son transferibles y objetivables, las representaciones sociales son imposibles sin comunicación, en tanto en su génesis, como en su vida y evolución, las representaciones sociales se constituyen en su 
integridad por datos exclusivamente construidos por la vía de las mediación comunicativa; es decir, producidos y reproducidos a través de sistemas más o menos complejos de circulación de mensajes, o sea, de interacciones comunicativas entre los individuos".

Por lo anteriormente expuesto es necesario aceptar y enfatizar el papel cada vez más determinante de los medios de comunicación de masas en la creación y la difusión de informaciones, opiniones e ideas. Es por esto que el análisis de las representaciones que son transmitidas por los medios se torna necesario. No en vano Moscovici ha caracterizado nuestro tiempo como la época por excelencia de las representaciones sociales.

Es precisamente en el campo de la comunicación social donde veo una gran necesidad de contar con un acercamiento a los fenómenos comunicacionales que trate de indagar tanto las representaciones sociales sobre ciertos temas, o acontecimientos que hacen circular los medios como la manera en que las personas se representan una serie de conceptos y nociones que, en gran parte, son trasmitidos por los medios.

\section{La investigación.}

Una vez planteada la problemática teórica en la que se inscribe esta investigación, pasaré a describir la metodología que he adoptado, las características del corpus de estudio y finalmente presentaré algunos de los resultados del análisis de la entrevista semidirigida que se aplicó. Existen diferentes enfoques metodológicos para el estudio de las representaciones

sociales que implican el uso de diferentes instrumentos y métodos de análisis ; para este estudio he retomado una propuesta metodologica

${ }^{5}$ De acuerdo con Ma. Auxiliadora Banchs las propuestas para el estudio de las representaciones sociales se podrían agrupar en dos enfoques: el enfoque estructural y el procesual. El estructural se centra en la estructura de las representaciones, haciendo uso del método experimental, o bien de análisis multivariables que permiten identificar dicha organización. El procesual trata de abordar los dos tipos de procesos que inciden en la conformación de representaciones sociales: a) los procesos cognitivos mentales, de carácter individual y b) los procesos de interacción y contextuales de carácter social. La investigación de Grize, et al. puede ser considerada como procesual ya que en ella no sólo se identifican los contenidos de las representaciones sino también se indaga su proceso de formación. Cf. Banchs, M. Auxiliadora "Aproximaciones procesuales y estructurales al estudio de las representaciones sociales", en Papers on Social Representations, Vol. 9, 2000, Electronic Version. 
que está fundamentada sustancialmente en el estudio realizado por Grize, et al. Los asalariados frente a las nuevas tecnologias (1987) ya que en esa investigación están incorporados diferentes avances tanto de la psicología social, la sociología y la lógica natural que permiten interpretar y analizar las representaciones sociales.

Esta propuesta aborda una doble perspectiva de las ciencias sociales. Por un lado, se tiene en cuenta una dimensión práctica, ideológica y cultural; por el otro, una dimensión cognitiva. De esta manera, se revisan todos los espacios en donde las representaciones se generan y sustentan como fenómeno sociológico y psicológico.

Este acercamiento metodológico implica trabajar con representaciones discursivas que se expresan en las respuestas verbales de los sujetos. Para esto, se sugiere aplicar una entrevista semidirigida con una muestra representativa. Para la elaboración del instrumento se toman en cuenta tres situaciones complementarias: a) selección de elementos significativos, que indican cuáles son los principales elementos del preconstruido cultural del encuestado, gracias a preguntas de evocación incluidas en la entrevista; b) construcción de esquemas de relaciones, por medio de preguntas en que el encuestado debe ordenar distintos conceptos en grupos, para recoger información sobre los sistemas, asociaciones y las redes de significación en las que intervienen los elementos puestos en evidencia por el momento de activación anterior y c) la producción de discurso argumentativo, donde se integran elementos situacionales y el contexto de la encuesta.

De este acercamiento metodológico he retomados tres métodos para abordar el objeto de estudio: 1) un sistema de categorías; 2) la decodificación documental y 3) el análisis argumentativo.

Esta metodología de estudio une un sistema cuantitativo de categorías a un análisis argumentativo, que obtiene resultados más cualitativos. Describiré brevemente cada uno de estos métodos.

\section{1.- Los sistemas de categorías en la evocación y en las conductas discursivas.}

Un primer acercamiento a la información obtenida es a través del análisis de contenido, el cual se funda sobre un proceso de generalización - que no implica perder la fineza del análisis. El sistema que se utiliza es una matriz de análisis que se puede denominar tipología; es un sistema de clasificación o sistema de categorización. Dicha matriz debe ser apropiada y específica al tipo de información 
que se va a analizar y es utilizada para el análisis de la evocación y las conductas discursivas.

La evocación. Si consideramos que las representaciones son a la vez un proceso y un contenido de conocimiento, un primer nivel de cuestionamiento es el de la evocación espontánea y la selección de elementos significativos producidos por un ítem que sirve de estímulo. La persona que responde se refiere al universo cognitivo de la noción y actualiza por medio de un conjunto de palabras o expresiones el espacio de significación del ítem propuesto. A partir de las palabras empleadas en la evocación, el análisis de contenido se propone ofrecer un cierto orden a la gran cantidad de información correspondiente a la verbalización. Ese orden es el producto de un sistema de hipótesis sobre la naturaleza de las representaciones sociales.

Los campos semánticos. Posteriormente, la información obtenida es retomada a través de un procedimiento operatorio de recorte de los cạmpos de referencia en el discurso de los sujetos. Los campos semánticos que por lo general aparecen son el campo económico, el político, el de valores y normas (o axiológico) y el social, así como, y en el caso de trabajar con las identidades, el cultural.

El análisis de las conductas discursivas. El discurso debe ser tratado a nivel de razonamiento y de comunicación. Por lo tanto, las representaciones no pueden simplemente identificarse con una organización de contenidos, ya que surgen de una situación de intercambio, sino en relación con las condiciones de producción del discurso.

Existe la necesidad de reunir en una misma noción los elementos que revelan los contenidos del discurso y los elementos que revelan los comportamientos, es decir, las conductas discursivas. Se trata, por un lado, de las diversas maneras en las que el locutor desarrolla los objetos o tópicos de su discurso y, por otro, la manera en que se compromete con los enunciados (implicación del locutor).

Los modos discursivos. Éstos designan la manera en que el locutor expone los contenidos de su discurso; en otras palabras, la actitud cognitiva que manifiesta en la enunciación de esos contenidos. Generalmente aparecen los siguientes modos:

- El constativo. Es en el que el sujeto se presenta como testigo y describe o constata los hechos, los acontecimientos y las cosas: "Me gusta comunicar a la gente".

- El proyectivo. Aquí el sujeto anticipa el porvenir, predice y hace proyecciones: "Medio por el cual me voy a poder expresar". 
- El axiológico. El sujeto hace un juicio sobre los hechos o acontecimientos: "Comunicar a una sociedad correctamente y dándole una información adecuada".

- El prescriptivo. El sujeto da su opinión sobre algo que se hará o no, da un consejo. Es una forma atenuada de las órdenes o las prohibiciones: "Lo que debes darle a las personas y qué cosas no debes darle".

- El metadiscursivo. El locutor tematiza la situación de entrevista o el contenido de sus propio discurso: "Como tú sabes, el campo es muy amplio".

La presencia del locutor. Ésta es estimada por el grado de compromiso que tiene el locutor frente a lo que enuncia. En un enunciado, el locutor puede estar presente de dos modos diferentes: por un lado, puede estar incluido en el contenido proposicional del enunciado y puede figurar bajo la forma de un pronombre personal. Por el otro, puede estar presente en tanto que enunciador del contenido proposicional, en cuyo caso es capaz de expresar diversas actitudes frente al enunciado: certeza, duda, juicio, etc.

\section{El sistema de decodificación documental de los lugares de determinación.}

El sistema de señalamiento de los lugares de determinación y de sus modalidades en el discurso no es una categorización que conduzca a un análisis de contenido; se busca con él descubrir la presencia/ ausencia de marcas o lugares de determinación en el discurso. Por ello, su decodificación no es más que la transformación de un corpus en una base documental. Lo que se busca es mostrar las relaciones que efectúa cada sujeto a partir de los elementos tomados de uno o varios lugares de determinación.

Tres lugares de determinación pueden ser identificados:

a) La determinación por la ideología. Para seguir la lógica del sistema teórico adoptado, es necesario analizar el funcionamiento de la ideología en el discurso. El compromiso del sujeto con su posición ideológica, que uno frecuentemente juzga de pasional, se expresa por la valoración de ciertos temas. Sin embargo, no toda valoración en una entrevista puede ser considerada como una huella de la ideología. Decir que una representación se convierte en ideológica porque es pasional (incluye valorizaciones, modalizaciones) o es una acción (performativa) supone que existe un estado neutro de la representación. 
Estado en el que sólo se encontraría información sin opinión, sin comentario. La ideología se lee en las justificaciones y racionalizaciones que el sujeto expresa para apoyar sus ideas. Esa forma argumentativa refleja un proceso de acomodación del sujeto a la presión que la sociedad y el poder hacen pesar sobre él o, es más, es un proceso de interiorización de valores. Pero, en muchos casos la relación no es evidente, ya que uno puede expresar una posición ideológica bajo la forma de la evidencia.

b) Las matrices culturales de interpretación (o preconstruidos). Ellas son la manifestación de una cierta memoria colectiva, a través de la cual se pueden entender muchas de las expresiones que se repiten de un sujeto a otro. Éstas son adquiridas a través de las instituciones con las que la sociedad está dotada, escuelas, iglesias, familias, etc.

c) El relato de la práctica. Las experiencias de un sujeto son un elemento importante para el funcionamiento del discurso. Por ejemplo, los efectos de la estructura social sobre el individuo y su posición socio-económica en ella, son datos relevantes cuando se trata de analizar las representaciones.

\section{El análisis argumentativo.}

Las representaciones sociales que circulan en los discursos, son vehiculizadas por las palabras, los mensajes y las imágenes de los medios de comunicación y son cristalizadas en las conductas de los individuos y las comunidades. La comunicación juega, en este proceso, un rol fundamental en el intercambio e interacción que concurren a la creación de un universo consensual. De ahí que las representaciones sociales tengan que ser abordadas, a la vez como el proceso y el producto de una actividad de apropiación de la realidad externa a la producción del pensamiento y de la elaboración psicológica y social de esta realidad.

En esta apropiación de la realidad, el lenguaje juega un rol fundamental. La función mediadora del lenguaje, según Roig, presupone una ampliación metodológica que permite leer en el nivel discursivo la contextualidad social que constituye el marco de condiciones de toda producción simbólica (en Ponte, 1999:26).

La actividad discursiva es el lugar donde las representaciones sociales se expresan de la manera más compleja. Por ende, la metodología elegida está centrada en la dimensión argumentativa de esta actividad. Según Grize, et al. (1987) no existe un discurso donde 
esta faceta argumentativa no esté presente, al.menos en algún grado. Para él, la actividad discursiva es, sin duda, la expresión más compleja a la que pueden dar lugar las representaciones sociales. No existe discurso que no sea un poco elaborado y que no presente huellas de argumentación. Cuando se trabaja con instrumentos que buscan respuestas informativas, el sujeto interrogado, en la gran mayoría de los casos, se involucra en una serie de desarrollos explicativos, toma posición, expresa su pensamiento, examina los pros y los contras, etc. En otras palabras, el sujeto elabora un micro universo complejo y coherente, dotado de una cierta autonomía y frente al cual, la pregunta hecha aparece como un simple detonador.

Las representaciones sociales se encuentran preferentemente en las conversaciones ordinarias y en el espacio social informal, donde el devenir de las asociaciones y las prevalencias emocionales poseen un campo fértil para germinar. En los enunciados que se producen en aquellas situaciones, los sujetos entrelazan narraciones, descripciones y argumentos que son contenedores de las imágenes adquiridas y reformuladas que determinan a las representaciones. De estos tres estilos enunciativos, nos interesa el nivel argumentativo del discurso, por tratarse de una actividad que elabora razonamientos a partir de una base de valores socioculturales compartidos, sin necesariamente poseer premisas ni requerir razonamientos lógicos demostrables para construir los objetos del discurso.

El tema de la argumentación es una área de investigación en la que Grize ha trabajado durante largo tiempo (Cf. Grize 1982, 1992). Existen varios textos en los que aborda tanto el problema teórico como el metodológico. En la investigación sobre las nuevas tecnologías, la metodología seleccionada es, a mi parecer, demasiado compleja. Por esta razón, he retomado otra propuesta de Grize (Véase Gutiérrez, 1991) que permite detectar entre otras cosas, el involucramiento del locutor, los juicios o valores que sustentan una argumentación, las operaciones mediante las cuales se logra la credibilidad del discurso, así como la construcción misma de la argumentación.

\section{El corpus de estudio.}

A continuación describo brevemente el instrumento utilizado para la recolección de los datos y el corpus de estudio que se obtuvo por medio de este instrumento. Siguiendo los lineamientos metodológicos antes presentados, decidí utilizar como instrumento una entrevista 
semidirigida. Esta entrevista fue aplicada a 100 alumnos $^{6}$ de la carrera de comunicación social de la Universidad Autónoma Metropolitana, Unidad Xochimilco durante el trimestre que inició en septiembre del 2002. Se buscó que los alumnos fueran de diferentes trimestres para así tener elementos de comparación y saber si el contacto con los contenidos de los diferentes módulos modificaba o no la representación inicial; los alumnos entrevistados fueron: 34 alumnos de nuevo ingreso que cursan el tronco interdivisional, 33 de quinto que forma parte del tronco básico de carrera y 33 de onceavo trimestre que corresponde al tronco terminal ${ }^{7}$.

En la entrevista semidirigida primeramente se les dio un cuestionario en el cual tenían que vaciar información sobre edad, sexo y su relación con los medios. Dado que los sujetos son alumnos de comunicación consideré importante recabar información sobre su consumo de medios ya que dicho consumo funciona como elemento de sus preconstruidos y además puede proporcionar información útil que puede ser cruzada con otras variables. Las preguntas están formuladas de la siguiente manera: ¿qué noticiarios de televisión ves frecuentemente?, ¿qué estación de radio utilizas para informarte?, ¿qué periódicos lees habitualmente?, ¿cuáles son tus programas preferidos: televisión, radio? Así como una serie de preguntas en las que se les interrogaba sobre su conocimiento de las personas que trabajan en televisión, radio y prensa ${ }^{8}$.

Para obtener información sobre los contenidos de las representaciones sociales en el diseño del instrumento se tomaron en cuenta las tres dimensiones a partir de las cuales, es posible analizar, con fines didácticos y empíricos, las representaciones sociales como "universos de opinión": la información, el campo de representación y la actitud (Moscovici 1979:49). Cada una de las preguntas fue diseñada teniendo en mente alguna de las dimensiones antes mencionadas. Se

${ }^{6}$ Este trabajo no hubiera sido posible sin la ayuda de mis alumnas de Servicio Social: Adriana Hernández, Karina Nolazco y Dunia Campos quienes realizaron las entrevistas y trascribieron la información.

${ }^{7}$ Tratando de que la muestra fuera lo más representativa posible decidí entrevistar al 33\% de los alumnos de los niveles elegidos, es decir de los 100 alumnos que cursan uno de los módulos de los tres troncos de la carrera( $1^{\circ}, 5^{\circ}, 11^{\circ}$ ) se entrevistó aproximadamente al $33 \%$; la selección fue al azar.

${ }^{8}$ El vaciado de esta información de inicio arroja datos interesantes sobre el consumo de medios por parte de los sujetos que son de utilidad para identificar las representaciones que tienen sobre el campo de comunicación. Los resultados de esta parte darían para escribir un artículo sobre el tema. 
utilizaron tres tipos de preguntas: una serie de-preguntas abiertas, una pregunta de evocación y otra de complementación.

\section{Resultados preliminares.}

La presentación de los resultados de la entrevista semidirigida sigue el criterio de ubicación de los tres "universos de opinión". Si bien como se verá en algunos casos el recorte o de cada una de estas dimensiones es complejo, el uso de este análisis dimensional nos proporciona información sobre el contenido y sentido de las representaciones sociales.

\section{Campo de representación}

Esta dimensión expresa la organización del contenido de la representación social en forma jerarquizada, variando de grupo a grupo e inclusive al interior del mismo grupo. Permite visualizar el carácter del contenido, las prioridades cualitativas o imaginativas, en un campo que integra informaciones en un nuevo nivel de organización en relación a sus fuentes inmediatas.

Como señala Moscovici: "La dimensión que designamos por medio del vocablo 'campo de representación' nos remite a la idea de imagen, de modelo social, al contenido concreto y limitado de las proposiciones que se refieren a un aspecto preciso del objeto de la representación. La noción de dimensión nos obliga a estimar que existe un campo de representación, una imagen, allí donde hay una unidad jerarquizada de los elementos" (1979:46). Lo que engloba esta dimensión es la imagen que tienen del campo, la práctica con la que está más relacionada y la imagen del comunicador.

Para poder indagar cuál es el campo de representación se utilizó primeramente una pregunta de evocación formulada de la siguiente manera: ¿Qué palabras te vienen a la mente cuando escuchas la expresión comunicación social ${ }^{y}$ ?

Las preguntas de evocación tienen la finalidad de conocer los preconstruidos culturales en los que se basa la representación. A pesar de su simplicidad formal, las preguntas de evocación implican un

${ }^{9}$ En un primer momento del diseño del instrumento el ítem de evocación fue el de "comunicación", pero en el estudio exploratorio del instrumento me di cuenta que este ítem era demasiado extensivo y que los sujetos respondían cuestiones tan generales como teléfono, satélite, etc. Por eso decidí substituirlo por "comunicación social" para evitar este problema y porque finalmente los alumnos de la muestra son estudiantes de comunicación social. 
alto grado de abstracción. Los sujetos no propomen cualquier palabra o expresión para cumplir con el contrato moral consistente en responder a las preguntas que se les hacen. Más bien hacen un esfuerzo por expresar los elementos que se asociaron a las palabras utilizadas como estímulo. Las repuestas se refieren al universo cognitivo de la noción y corresponden a las expresiones asociadas a la noción propuesta. Un primer análisis es el análisis de contenido que comienza con un análisis de equivalencias, definidas como categorías de diferentes campos de enunciación.

\section{Frecuencia de palabras relacionadas con la expresión comunicación social}

\begin{tabular}{|c|c|c|c|}
\hline $\begin{array}{l}\text { Social } \\
(74) \\
28.90 \%\end{array}$ & $\begin{array}{l}\text { Comunicativo } \\
\text { (75) } \\
29.29 \%\end{array}$ & $\begin{array}{l}\text { Tecnológico } \\
\text { (medios) (83) } \\
32.42 \%\end{array}$ & \begin{tabular}{|l|} 
Axiológico \\
$(24)$ \\
$9.37 \%$ \\
\end{tabular} \\
\hline $\begin{array}{l}\text { Sociedad } 27 \\
\text { Comunicación } 11 \\
\text { Gente } 10 \\
\text { Cultura } 8 \\
\text { Interacción } 3 \\
\text { Convivir } 2 \\
\text { Problemas } \\
\text { sociales 2 } \\
\text { Organizaciones } \\
\text { públicas 2 } \\
\text { Política 2 } \\
\text { Comunidad } 2 \\
\text { Conocer 2 } \\
\text { Gestión social 1 } \\
\text { Masa 1 } \\
\text { Ideas 1 }\end{array}$ & $\begin{array}{l}\text { Información } 21 \\
\text { Expresión } 11 \\
\text { Mensaje } 7 \\
\text { Comunicar } 7 \\
\text { Difusión 4 } \\
\text { Código 2 } \\
\text { Emisor 2 } \\
\text { Receptor 2 } \\
\text { Investigación 2 } \\
\text { Escribir 2 } \\
\text { Hablar 2 } \\
\text { Dialogar 2 } \\
\text { Palabras 2 } \\
\text { Lenguaje 2 } \\
\text { Opinión 1 } \\
\text { Ideas 1 } \\
\text { Difusión 1 } \\
\text { Imágenes 1 } \\
\text { Licenciatura 1 } \\
\text { Voz 1 } \\
\text { Estudio 1 }\end{array}$ & $\begin{array}{l}\text { Medios de } \\
\text { comunicación } 20 \\
\text { Televisión } 18 \\
\text { Radio } 18 \\
\text { Prensa } 11 \\
\text { Cine 6 } \\
\text { Periodismo 6 } \\
\text { Fotografía 2 } \\
\text { Noticias } 1 \\
\text { Dibujo } 1\end{array}$ & $\begin{array}{l}\text { Manipulación } 2 \\
\text { Compromiso 2 } \\
\text { Verdad 2 } \\
\text { Ética 2 } \\
\text { Crítica 1 } \\
\text { Análisis 1 } \\
\text { Objetividad 1 } \\
\\
\text { Claridad 1 } \\
\\
\text { Cordialidad 1 } \\
\text { Imparcialidad 1 } \\
\text { Disciplina 1 } \\
\text { Pasión 1 } \\
\text { Alegría 1 } \\
\text { Ayuda 1 } \\
\text { Pensar 1 } \\
\text { Imaginación } 1 \\
\text { Creatividad 1 } \\
\text { Preparación 1 } \\
\text { Libertad 1 } \\
\text { Ideología 1 }\end{array}$ \\
\hline
\end{tabular}


Las palabras se ubican principalmente en el campo tecnológico seguido por el comunicativo que está prácticamente empatado con el social. Aquí es importante señalar que si bien la frase de evocación de la pregunta era "comunicación social" y que además la palabra social es una de las que más se repite, el campo tecnológico es el que predomina. Originalmente no se pensó en el campo comunicativo pero dado que muchas de las palabras tienen que ver más con la idea de la comunicación como intercambio de información o de ideas se ubicaron en este campo todas las palabras que tienen ese sentido ${ }^{10}$ Esto me lleva a interpretar que finalmente la imagen que todavía prevalece sobre lo que es la comunicación social está anclada en ciertos preconstruidos culturales en los que la comunicación tiene que ver, fundamentalmente, con los medios de comunicación masiva.

En el plan de estudios de la carrera de comunicación social de la UAM se señalan como objetivos los siguientes:

Formar profesionales de la comunicación conscientes de las condiciones socioeconómicas, políticas en las que se inscriben los procesos de comunicación social; que interpreten y transformen, desde una perspectiva racional, sistemática y crítica, las prácticas de la comunicación en México; además de que puedan diseñar estrategias de comunicación a partir del análisis crítico de los campos donde se ubican las prácticas comunicativas; y comprendan y utilicen creativamente los lenguajes y técnicas propios de la comunicación, en función de la solución de problemas sociales".

Menciono estos objetivos porque dos de las preguntas abiertas tienen que ver tanto con las funciones que tiene la comunicación social como con el campo de trabajo en el que se desempeña un egresado de esta carrera.

Con el fin indagar cuál es el campo laboral en el que, de acuerdo a ellos, se desempeña un comunicador, se les formulo la siguiente pregunta: ¿Cuál es el campo profesional del comunicador social?

${ }^{10} \mathrm{El}$ análisis de las preguntas de evocación no termina aquí. Después de ubicar las frecuencias y los campos se pasa a un análisis de equivalencias en el que se trabajan las catcgorías ligadas a la palabra de evocación. Xochimilco.

Folleto de presentación de la carrera de Comunicación Social de la UAM 


\section{Campo de trabajo}

\begin{tabular}{|l|l|l|}
\hline $\begin{array}{l}\text { Medios de } \\
\text { comunicación } \\
79.60 \%\end{array}$ & $\begin{array}{l}\text { Academía } \\
\text { 3.36\% }\end{array}$ & $\begin{array}{l}\text { Ambito público/privado } \\
17.04 \%\end{array}$ \\
\hline Radio 62 & Investigación 5 & $\begin{array}{l}\text { Oficinas gubernamen- } \\
\text { tales 13 }\end{array}$ \\
\hline Prensa 60 & Docencia 3 & Empresas 15 \\
\hline Televisión 58 & Docentes 2 & En cualquier campo 7 \\
\hline Cine 31 & Investigador 1 & $\begin{array}{l}\text { Departamento de } \\
\text { comunicación social 6 }\end{array}$ \\
\hline $\begin{array}{l}\text { Medios de } \\
\text { comunicación 22 }\end{array}$ & Investigaciones & $\begin{array}{l}\text { Instituciones públicas } \\
\text { dedicadas a la comunicación 5 }\end{array}$ \\
\hline Fotografía 11 & & $\begin{array}{l}\text { Organizaciones } \\
\text { gubernamentales 4 }\end{array}$ \\
\hline Publicidad 9 & & Campañas políticas 3 \\
\hline Internet 5 & & Recursos Humanos 2 \\
\hline Revistas 4 & & Ámbito de gobierno 1 \\
\hline Medios impresos 4 & & Casas de cultura 1 \\
\hline Medios Visuales 3 & & Galerías 1 \\
\hline Mercadotecnia 2 & & Teléfonos 1 \\
\hline Producción 2 & & Telégrafos 1 \\
\hline Guionismo 2 & & Asociaciones civiles 1 \\
\hline Arte 2 & & \\
\hline Locutor 2 & & \\
\hline Diseño 1 & & \\
\hline Cómic 1 & & \\
\hline Donde haya un & & \\
\hline emisor y un receptor 1 & & \\
\hline Arte 1 & & \\
\hline Reportero 1 & & \\
\hline
\end{tabular}

Por las respuestas que arrojó la entrevista se puede observar que en términos de la representación que tienen los alumnos de la comunicación, el campo de trabajo de un comunicador tiene que ver particularmente con los medios. Aunque en el folleto que se les proporciona a los alumnos al ingreso se especifica que el campo de trabajo es: tanto los medios masivos de comunicación, organismos del Estado, organismos no gubernamentales, en las universidades e institutos de investigación y en todas aquellas situaciones donde se produce el intercambio y la transformación de productos comunicacionales, son muy pocas las menciones que tienen que ver con otros ámbitos laborales que no sean los medios. 


\section{Dimensión de la información}

Esta dimensión tiene que ver con la organización o suma de conocimientos con que cuenta un grupo acerca de un acontecimiento, hecho o fenómeno de naturaleza social. Conocimientos que muestran particularidades en cuanto a cantidad y calidad de los mismos; carácter estereotipado o difundido sin soporte explícito. Siguiendo a Moscovici, esta dimensión se relaciona con "la organización de los conocimientos que posee un grupo respecto a un objeto social" (1979:45). Para indagar qué tipo de información poseen los alumnos sobre la función de la comunicación social se les hizo la siguiente pregunta: ¿Para ti qué es la comunicación social?

\section{Funciones de la comunicación social ${ }^{12}$}

\begin{tabular}{|c|c|c|}
\hline $\begin{array}{l}\text { Intercambio de } \\
\text { información } \\
37 \\
36.63 \%\end{array}$ & \begin{tabular}{|l|} 
Estudio de los medios \\
de comunicación \\
masiva \\
13 \\
$12.88 \%$ \\
\end{tabular} & $\begin{array}{l}\text { Proporcionar/aportar } \\
\text { información a la sociedad } \\
51 \\
50.50 \%\end{array}$ \\
\hline Información 4 & Análisis de los medios 5 & $\begin{array}{l}\text { Estar en contacto con la } \\
\text { sociedad } 11\end{array}$ \\
\hline Formas de expresión 11 & $\begin{array}{l}\text { Estudio de las formas } \\
\text { del lenguaje } 2\end{array}$ & $\begin{array}{l}\text { Dar información a la } \\
\text { sociedad correctamente } 10\end{array}$ \\
\hline $\begin{array}{l}\text { Dar a conocer } \\
\text { información } 6\end{array}$ & $\begin{array}{l}\text { Un crisol de } \\
\text { posibilidades } 1\end{array}$ & $\begin{array}{l}\text { Relacionar a los medios de } \\
\text { comunicación con los } \\
\text { problemas que tiene la } \\
\text { sociedad } 14\end{array}$ \\
\hline $\begin{array}{l}\text { Transmisión de } \\
\text { mensajes } 6\end{array}$ & Una forma de vida $T$ & \begin{tabular}{|l|} 
Forma de fomentar cultura 1 \\
Generan interacciones en \\
distintos grupos sociales 3 \\
\end{tabular} \\
\hline Difusion de ideas 5 & Mi vocación 1 & Estudiar a la sociedad 1 \\
\hline $\begin{array}{l}\text { Encontrar los mensajes } \\
\text { adecuados } 2\end{array}$ & $\begin{array}{l}\text { Nuevas formas de } \\
\text { comunicación } 2\end{array}$ & \begin{tabular}{|l|} 
Ciencia que recicla \\
información para difundirlo \\
a la sociedad 1 \\
\end{tabular} \\
\hline Formas de pensamientol & \begin{tabular}{|l|}
$\begin{array}{l}\text { Medios por los cuales } \\
\text { se transmite } \\
\text { información } 1\end{array}$ \\
\end{tabular} & $\begin{array}{l}\text { La comunicación de la } \\
\text { sociedad } 1\end{array}$ \\
\hline $\begin{array}{l}\text { Elaboración de } \\
\text { mensajes } 1\end{array}$ & & $\begin{array}{l}\text { Medio para influir en la } \\
\text { sociedad } 3\end{array}$ \\
\hline \multirow[t]{2}{*}{$\begin{array}{l}\text { Intercambio de } \\
\text { ideologías } 1\end{array}$} & & $\begin{array}{l}\text { Lograr armonía/ equilibrio } \\
\text { en la sociedad } 3\end{array}$ \\
\hline & & \begin{tabular}{|l|} 
Formar profesionales que \\
tengan un pensamiento crítico 3
\end{tabular} \\
\hline
\end{tabular}


Un primer comentario que se desprende de estos datos es que si bien la representación que tienen los estudiantes entrevistados sobre qué es la comunicación social es aquélla que tiene que ver con proporcionar información a la sociedad, es significativo el hecho de que si sumamos los otros dos campos quedan casi empatados. Esta representación coincide con lo que muchos años fue el paradigma dominante en la "Communication research" en la que se consideraba que la función fundamental de la comunicación masiva era la de transmitir información (Cf. Wolf, M 1991).

Para complementar el análisis cuantitativo, he analizado las respuestas a la misma pregunta desde un método más cualitativo: el análisis de los modos discursivos. Este nivel de análisis tiene que ver fundamentalmente con el análisis del discurso producido por los entrevistados. Como ya anteriormente había señalado, las representaciones no pueden simplemente identificarse con una organización de contenidos, ya que surgen de una situación de intercambio, sino en relación con las condiciones de producción del discurso. Los modos discursivos designan la manera en que el locutor expone los contenidos de su discurso; en otras palabras, la actitud cognitiva que manifiesta en la enunciación de esos contenidos. A continuación presento un cuadro que sintetizan los modos que aparecen en las respuesta a la pregunta:

\begin{tabular}{|c|c|c|}
\hline \multicolumn{3}{|c|}{ ¿Para ti qué es la comunicación social' ${ }^{13}$ ? } \\
\hline CONSTATIVO & AXIOLÓGICO & PROYECTIVO \\
\hline $\begin{array}{l}\text { Es una herramienta para } \\
\text { mejorar la comunicación } \\
\text { en la sociedad. }\end{array}$ & $\begin{array}{l}\text { Informar de manera yo } \\
\text { creo objetiva y crítica. }\end{array}$ & $\begin{array}{l}\text { Es el medio por el } \\
\text { cual me voy a poder } \\
\text { expresar. }\end{array}$ \\
\hline $\begin{array}{l}\text { La carrera que engloba } \\
\text { el tratamiento de los } \\
\text { medios y la relación } \\
\text { entre personas. }\end{array}$ & $\begin{array}{l}\text { Es el hecho de comunicar } \\
\text { a una sociedad } \\
\text { correctamente y dándole } \\
\text { información adecuada. }\end{array}$ & \\
\hline $\begin{array}{l}\text { Es el medio por el cual } \\
\text { se transmiten mensajes. }\end{array}$ & $\begin{array}{l}\text { Es la que nos permite } \\
\text { llevar buenas relaciones } \\
\text { con todas las personas. }\end{array}$ & \\
\hline \multicolumn{3}{|l|}{$\begin{array}{l}\text { Es una herramienta para } \\
\text { informar y ayudar. }\end{array}$} \\
\hline \multicolumn{3}{|l|}{$\begin{array}{l}\text { Es la forma de dar a } \\
\text { conocer algo ante la } \\
\text { sociedad. }\end{array}$} \\
\hline $\begin{array}{l}\text { Es un proceso de } \\
\text { informacion. }\end{array}$ & & \\
\hline
\end{tabular}

y no tanto los campos en los que se aglutinan las respuestas.

${ }^{13}$ Aquí sólo mostramos algunos de los ejemplos más representativos y no 


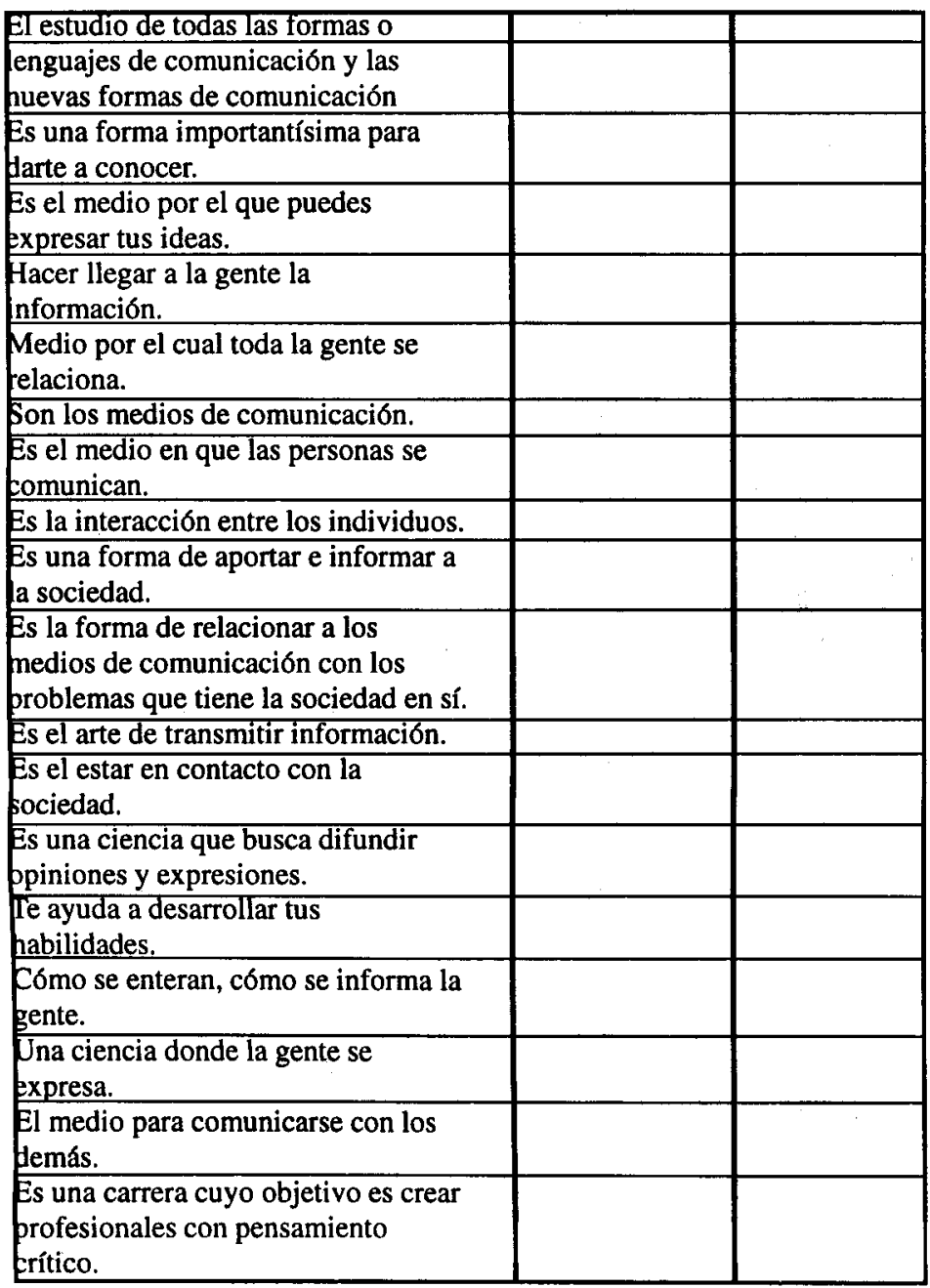

Es importante señalar que cuando la pregunta está dirigida a un ámbito más general, como el definir lo que es un campo, existe poco involucramiento del entrevistado $y$, por lo tanto, predomina el modo constativo. Este tipo de análisis nos muestra el grado de acercamiento al tema por parte de los entrevistados. En este caso predomina el modo constativo porque los datos que se les solicitan tienen que ver más con la información que poseen los sujetos sobre el objeto social, en

las frecuencias ya que en el momento de redactar este artículo se tenían los porcentajes por trimestre pero no los datos integrados. 
este estudio, la comunicación social y no tanto los valores a la que la asocian.

Dimensión de la actitud.

Esta dimensión tiene que ver con "la orientación global en relación con el objeto de la representación social" (Moscovici 1979:47). Se puede considerar como el componente más aparente, fáctico y conductual de la representación. Es la dimensión más frecuente ya que como señala Moscovici "nos representamos una cosa únicamente después de haber tomado posición y en función de la posición tomada" (1979:49).

Para poder identificar la motivación que los llevó a elegir la carrera de comunicación social se les hizo la siguiente pregunta: ¿Por qué decidiste estudiar comunicación social?

\section{Motivaciones}

\begin{tabular}{|l|l|l|l|}
\hline $\begin{array}{l}\text { Sin interés } \\
\text { específico 19 } \\
19 \%\end{array}$ & $\begin{array}{l}\text { Interés individual } \\
18 \\
18 \%\end{array}$ & $\begin{array}{l}\text { Interés en el } \\
\text { campo 46 } \\
46 \%\end{array}$ & $\begin{array}{l}\text { Interés en lo social } \\
17 \\
17 \%\end{array}$ \\
\hline Por casualidad 4 & $\begin{array}{l}\text { Comunicar lo que } \\
\text { pienso, siento 5 }\end{array}$ & $\begin{array}{l}\text { Trabajar en los } \\
\text { medios de } \\
\text { comunicación 18 }\end{array}$ & $\begin{array}{l}\text { Crear conciencia } \\
\text { en la gente 3 }\end{array}$ \\
\hline $\begin{array}{l}\text { Encontrar trabajo } \\
\text { fácilmente 3 }\end{array}$ & $\begin{array}{l}\text { Que la gente sepa } \\
\text { lo que pienso 2 }\end{array}$ & $\begin{array}{l}\text { Me gustan los } \\
\text { medios 14 }\end{array}$ & $\begin{array}{l}\text { Dar una solución a } \\
\text { los problemas que } \\
\text { tiene la sociedad 3 }\end{array}$ \\
\hline $\begin{array}{l}\text { Divertirme y } \\
\text { ganar dinero 3 }\end{array}$ & $\begin{array}{l}\text { Expresar mi punto } \\
\text { de vista 2 }\end{array}$ & $\begin{array}{l}\text { Llegar a ser } \\
\text { locutor 4 }\end{array}$ & Para conocer más \\
a la sociedad 1 \\
\hline $\begin{array}{l}\text { No encontré otra } \\
\text { carrera 2 }\end{array}$ & $\begin{array}{l}\text { Porque es mi } \\
\text { vocación 1 }\end{array}$ & $\begin{array}{l}\text { Porque es una } \\
\text { carrera que tiene } \\
\text { varias ramas 4 }\end{array}$ & $\begin{array}{l}\text { Para transmitir } \\
\text { algo a la sociedad } \\
1\end{array}$ \\
\hline $\begin{array}{l}\text { Por cosas o } \\
\text { problemas } \\
\text { personales 2 }\end{array}$ & $\begin{array}{l}\text { Desarrollar mi } \\
\text { creatividad y mi } \\
\text { potencial 1 }\end{array}$ & $\begin{array}{l}\text { Trabajar en } \\
\text { producción 3 }\end{array}$ & $\begin{array}{l}\text { Hacer las cosas } \\
\text { más fáciles a los } \\
\text { demás 1 }\end{array}$ \\
\hline $\begin{array}{l}\text { Se me hizo } \\
\text { atractivo 1 }\end{array}$ & $\begin{array}{l}\text { Vincular } \\
\text { cuestiones } \\
\text { artísticas con la } \\
\text { comunicación 1 }\end{array}$ & $\begin{array}{l}\text { Expresar algo por } \\
\text { medio de los } \\
\text { medios 2 }\end{array}$ & $\begin{array}{l}\text { Estoy en contra de } \\
\text { la manipulación de } \\
\text { los medios 1 }\end{array}$ \\
\hline $\begin{array}{l}\text { Para no estar en } \\
\text { una oficina 1 }\end{array}$ & $\begin{array}{l}\text { Tengo capacidad } \\
\text { verbal 1 }\end{array}$ & $\begin{array}{l}\text { Me interesó lo } \\
\text { audiovisual 1 }\end{array}$ & $\begin{array}{l}\text { Que la gente se de } \\
\text { cuenta del origen } \\
\text { de todos los } \\
\text { problemas 1 }\end{array}$ \\
\hline $\begin{array}{l}\text { Es la carrera } \\
\text { menos peor 1 }\end{array}$ & $\begin{array}{l}\text { Siento que es algo } \\
\text { en lo que puedo } \\
\text { destacar 1 }\end{array}$ & & $\begin{array}{l}\text { Es una forma de } \\
\text { estar más en } \\
\text { contacto con la } \\
\text { historia 1 }\end{array}$ \\
\hline
\end{tabular}




\begin{tabular}{|l|l|l|l|}
$\begin{array}{l}\text { El plan de } \\
\text { estudios 1 }\end{array}$ & $\begin{array}{l}\text { Para compartir lo } \\
\text { que yo sé 1 }\end{array}$ & Fomentar la cultura 1 \\
\hline $\begin{array}{l}\text { Reúne los } \\
\text { elementos } \\
\text { necesarios para la } \\
\text { comunicación 1 }\end{array}$ & $\begin{array}{l}\text { Me gusta el arte } \\
\text { de comunicar 1 }\end{array}$ & & $\begin{array}{l}\text { Para ayudar a la } \\
\text { sociedad 1 }\end{array}$ \\
\hline & $\begin{array}{l}\text { Para transmitir } \\
\text { mis sentimientos }\end{array}$ & $\begin{array}{l}\text { Tengo afinidades con } \\
\text { la sociología y la } \\
\text { antropología 1 }\end{array}$ \\
\hline & $\begin{array}{l}\text { Reflejar parte de } \\
\text { mí 1 }\end{array}$ & $\begin{array}{l}\text { Me gusta el enfoque } \\
\text { humano de la UAM 1 }\end{array}$ \\
\hline & & $\begin{array}{l}\text { En la sociedad hay que } \\
\text { reforzar ciertas cosas } \\
\text { que se han perdido 1 }\end{array}$ \\
\hline
\end{tabular}

Los datos sobre la motivación llaman la atención ya que un buen número de estudiantes afirman no tener una motivación específica (19\%) o afirman que decidieron estudiar comunicación para darse a conocer (18\%); es decir que gran parte del alumnado tiene la imagen de que el trabajo en el campo de la comunicación les permitirá ya sea ser famosos o expresar sus ideas y sentimientos. Si bien las respuestas se concentran más en la decisión de estudiar comunicación para poder trabajar en los medios, cuestión que coincide con la motivación que los impulsa a estudiar comunicación social, las demás respuestas proveen información importante para ubicar la imagen que tienen sobre el campo.

Ahora veamos el análisis de los datos de la misma pregunta pero desde el análisis de los modos discursivos.

\begin{tabular}{|c|c|c|c|}
\hline CONSTATIVO & AXIOLÓGICO & PROYECTIVO & PRESCRIPTIVO \\
\hline $\begin{array}{l}\text { Muestran cómo s } \\
\text { usan los medios } \\
\text { de comunicación. }\end{array}$ & $\begin{array}{l}\text { Es una carrera } \\
\text { interactiva. }\end{array}$ & $\begin{array}{l}\text { Me quiero dedicar } \\
\text { a la locución. }\end{array}$ & $\begin{array}{l}\text { Sería una forma de } \\
\text { expresión para mí. }\end{array}$ \\
\hline $\begin{array}{l}\text { Me llama la } \\
\text { atención. }\end{array}$ & $\begin{array}{l}\text { Puedo encontrar } \\
\text { trabajo más } \\
\text { fácilmente. }\end{array}$ & $\begin{array}{l}\text { Quisiera ser } \\
\text { locutor. }\end{array}$ & \\
\hline $\begin{array}{l}\text { Me gusta el } \\
\text { ambiente y } \\
\text { explicar las cosas }\end{array}$ & $\begin{array}{l}\text { Me gustan los } \\
\text { miedios y tengo } \\
\text { facilidad. }\end{array}$ & $\begin{array}{l}\text { Quiero analizar } \\
\text { los medios. }\end{array}$ & \\
\hline $\begin{array}{l}\text { Me interesan los } \\
\text { lenguajes con que } \\
\text { se manifiesta el } \\
\text { hombre. }\end{array}$ & $\begin{array}{l}\text { El nivel de cultura } \\
\text { de la gente es bajo }\end{array}$ & $\begin{array}{l}\text { Porque quiero ser } \\
\text { publicista. }\end{array}$ & \\
\hline
\end{tabular}




\begin{tabular}{|c|c|c|c|}
\hline $\begin{array}{l}\text { Divertirme y } \\
\text { ganar dinero }\end{array}$ & $\begin{array}{l}\text { La televísión se } \\
\text { basa en tu físico. }\end{array}$ & $\begin{array}{l}\text { Quiero influir en } \\
\text { los demás. }\end{array}$ & \\
\hline $\begin{array}{l}\text { Me gusta estar } \\
\text { informada. }\end{array}$ & $\begin{array}{l}\text { El radio es más } \\
\text { fuerte. }\end{array}$ & $\begin{array}{l}\text { Me quiero dedicar } \\
\text { a radio. }\end{array}$ & \\
\hline $\begin{array}{l}\text { Me identifico en } \\
\text { muchos aspectos. }\end{array}$ & $\begin{array}{l}\text { Porque implica } \\
\text { creatividad. }\end{array}$ & \begin{tabular}{|l|} 
Para ver cómo se \\
distribuyen los \\
mensajes.
\end{tabular} & \\
\hline $\begin{array}{l}\text { Me gusta lo que } \\
\text { es la tele, el radio }\end{array}$ & \begin{tabular}{|l} 
Por dar solución a \\
los problemas \\
sociales.
\end{tabular} & $\begin{array}{l}\text { Busco trabajar en } \\
\text { medios }\end{array}$ & \\
\hline \multirow{11}{*}{$\begin{array}{l}\text { Me gusta } \\
\text { comunicar a la } \\
\text { gente. }\end{array}$} & $\begin{array}{l}\text { Para crear } \\
\text { conciencia social. }\end{array}$ & & \\
\hline & $\begin{array}{l}\text { Se me hace una } \\
\text { carrera muy } \\
\text { interesante, muy } \\
\text { completa. } \\
\end{array}$ & & \\
\hline & $\begin{array}{l}\text { Me encanta } \\
\text { hablar, me encant } \\
\text { expresar. }\end{array}$ & & \\
\hline & $\begin{array}{l}\text { Está muy padre, } \\
\text { es algo muy } \\
\text { interesante. }\end{array}$ & & \\
\hline & $\begin{array}{l}\text { Me latió, fue la } \\
\text { que más me gustó }\end{array}$ & & \\
\hline & $\begin{array}{l}\text { Me agrada y es } \\
\text { indispensable. }\end{array}$ & & \\
\hline & \begin{tabular}{|l|} 
Siempre me ha \\
llamado la \\
atención. \\
\end{tabular} & & \\
\hline & $\begin{array}{l}\text { Me gusta mucho } \\
\text { la comunicación. }\end{array}$ & & \\
\hline & $\begin{array}{l}\text { Desde mi punto } \\
\text { de vista la } \\
\text { comunicación es } \\
\text { básica. }\end{array}$ & & \\
\hline & $\begin{array}{l}\text { Me gusta mucho } \\
\text { todo lo que tiene } \\
\text { que ver con } \\
\text { medios. }\end{array}$ & & \\
\hline & $\begin{array}{l}\text { Me gusta expresan } \\
\text { lo que siento y lo } \\
\text { que pienso. }\end{array}$ & & \\
\hline
\end{tabular}


Dada la naturaleza de la información que se solicita en la pregunta los entrevistados emiten directamente su opinión sobre lo que los motivó a estudiar comunicación social y, por lo tanto, hay un involucramiento del entrevistado que se manifiesta en el predominio del modo axiológico. Como se pude observar en los ejemplos, los alumnos emiten sus opiniones por medio de enunciados evaluativos que, generalmente, están acompañados por determinaciones cualitativas (bajo, interesante, indispensable).

La siguiente pregunta busca elicitar respuestas que proporcionen información tanto de la dimensión de la información como de la opinión o actitud. En el cuadro se han combinado tanto las frecuencias, los enunciados que proporcionan, así como el tipo de modo discursivo que predomina.

\section{¿Con cuáles comunicadores te identificas y por qué ${ }^{14}$ ?}

\begin{tabular}{|c|c|c|c|}
\hline Comunicador & & Razones & $\begin{array}{l}\text { Modo } \\
\text { discursivo }\end{array}$ \\
\hline $\begin{array}{l}\text { Cristina } \\
\text { Pacheco }\end{array}$ & 7 & $\begin{array}{l}\text { Porque cuenta historias. } \\
\text { Es una señora que tanto puede andar con la } \\
\text { gente más pobre y con la gente que está } \\
\text { hasta abajo, como puede irse a entrevistar } \\
\text { a la gente que tiene lanísima. } \\
\text { Le gusta ir más allá, a los sentimientos. } \\
\text { Me identifico con lo que escribe. } \\
\text { Se dedica al mismo asunto que yo me } \\
\text { quiero dedicar. }\end{array}$ & $\begin{array}{l}\text { Axiológico } \\
\text { Constativo } \\
\text { Axiológico }\end{array}$ \\
\hline \begin{tabular}{|l|} 
Víctor \\
Trujillo
\end{tabular} & 6 & $\begin{array}{l}\text { Por crítico. } \\
\text { Dice las cosas como las piensa. } \\
\text { Por su forma de dar las notas. } \\
\text { Porque era de aquí (de la UAM). } \\
\text { Lo que era antes de pasarse a Televisa. } \\
\text { La forma en que maneja las noticias y no } \\
\text { tiene una orientación política definida. }\end{array}$ & $\begin{array}{l}\text { Axiologico } \\
\text { Axiológico } \\
\text { Constativo } \\
\text { Axiológico } \\
\text { Axiológico } \\
\text { Axiológico }\end{array}$ \\
\hline $\begin{array}{l}\text { Con los } \\
\text { locutores de } \\
\text { radio }\end{array}$ & $k$ & $\begin{array}{l}\text { Están en esa lucha por la libertad de } \\
\text { expresión. } \\
\text { Como que soy así, soy de verdad muy } \\
\text { graciosa. } \\
\text { Se es más abierto en ese ámbito. } \\
\text { Realmente transmiten lo que está pasando. } \\
\text { Me gusta oír hablar así a la gente. }\end{array}$ & $\begin{array}{l}\text { Constativo } \\
\text { Axiológico } \\
\text { Axiológico } \\
\text { Axiologico } \\
\text { Constativo }\end{array}$ \\
\hline
\end{tabular}

${ }^{14}$ En la tabla se incluyen sólo aquellos comunicadores que tuvieron como mínimo dos menciones. 


\begin{tabular}{|c|c|c|c|}
\hline \begin{tabular}{|l} 
Javier \\
Solórzano
\end{tabular} & 5 & $\begin{array}{l}\text { Informa parcialmente, sabe muchas cosas. } \\
\text { Se me hace una gente muy culta. } \\
\text { Por su manera desenfadada de estar ante la } \\
\text { información. } \\
\text { Gente no tan quemada en los medios. } \\
\text { Me parece que es objetivo, me gustan sus } \\
\text { pláticas, la forma de comunicar es amena; } \\
\text { también cotorrea. } \\
\text { Es una persona actualizada, coherente y } \\
\text { sincera para lo que es la comunicación y el } \\
\text { trabajo. }\end{array}$ & $\begin{array}{l}\text { Axiologico } \\
\text { Axiologico } \\
\text { Axiologico } \\
\text { Axiologico } \\
\text { Axiologico } \\
\text { Axiológico }\end{array}$ \\
\hline $\begin{array}{l}\text { Carmen } \\
\text { Aristegui }\end{array}$ & 4 & $\begin{array}{l}\text { Se dedica realmente a hacer su trabajo y no } \\
\text { vive de la publicidad. } \\
\text { Me gusta su trabajo. } \\
\text { Me gusta su crítica. } \\
\text { No manipula la información y no tiene } \\
\text { miedo a decir las cosas tal y como son. } \\
\text { Es una persona actualizada, coherente y } \\
\text { sincera para lo que es la comunicación y el } \\
\text { trabaio. }\end{array}$ & $\begin{array}{l}\text { Axiológico } \\
\text { Axiológico } \\
\text { Axiologico } \\
\text { Axiologico } \\
\text { Axiológico }\end{array}$ \\
\hline $\begin{array}{l}\text { Ciro Gómez } \\
\text { Leiva }\end{array}$ & 4 & $\begin{array}{l}\text { Por su forma de dar las noticias. } \\
\text { La credibilidad es muy importante. } \\
\text { Es más abierto. Tiene menos censura. } \\
\text { Crítico pero cae en lo radical. }\end{array}$ & $\begin{array}{l}\text { Axiologico } \\
\text { Axiol6gico } \\
\text { Axiol6gico } \\
\text { Axiol6gico }\end{array}$ \\
\hline $\begin{array}{l}\text { Denise } \\
\text { Maerker }\end{array}$ & 3 & $\begin{array}{l}\text { Está muy preparada. } \\
\text { Entró a la televisión se hizo nefasta. } \\
\text { Es una chava muy preparada y que sabe } \\
\text { mucho. }\end{array}$ & $\begin{array}{l}\text { Axiologico } \\
\text { Axiologico } \\
\text { Axiologico }\end{array}$ \\
\hline Adela Micha & 3 & $\begin{array}{l}\text { La veo más tendenciosa, ahora su } \\
\text { profesionalismo se está deslavando un } \\
\text { poco. } \\
\text { Me gusta mucho su forma de trabajar. } \\
\text { Por la forma en como desarrolla toda la } \\
\text { información. }\end{array}$ & \begin{tabular}{l|} 
Axiológico \\
Constativo \\
Constativo
\end{tabular} \\
\hline \begin{tabular}{|l|} 
José \\
Gutiérrez \\
Vivó
\end{tabular} & 3 & $\begin{array}{l}\text { Trata de que realmente se haga algo por } \\
\text { solucionar las demandas que tienen las } \\
\text { personas. } \\
\text { Una persona muy bien preparada y no es } \\
\text { una persona que manipule la informacion } \\
\text { Me gusta cómo da las noticias. }\end{array}$ & $\begin{array}{l}\text { Axiologico } \\
\text { Axiologico } \\
\text { Axiologico }\end{array}$ \\
\hline $\begin{array}{l}\text { Wetmanzin } \\
\text { Rodríguez }\end{array}$ & 2 & $\begin{array}{l}\text { Me gusta cómo da las notas, lo hace más } \\
\text { accesible a la gente. } \\
\text { Aspiro a ser con él en la difusión }\end{array}$ & $\begin{array}{l}\text { Axiológico } \\
\text { Axiológico }\end{array}$ \\
\hline $\begin{array}{l}\text { Gustavo } \\
\text { García }\end{array}$ & 2 & $\begin{array}{l}\text { No está tan quemado en televisión. } \\
\text { Es una persona que sabe mucho de cine. }\end{array}$ & $\begin{array}{l}\text { Axiol6gico } \\
\text { Axiol6gico }\end{array}$ \\
\hline
\end{tabular}




\begin{tabular}{|c|c|c|c|}
\hline Jordi Soler & 2 & $\begin{array}{l}\text { Por los medios que toca. } \\
\text { Por llevar la información a un campo } \\
\text { cultural. }\end{array}$ & $\begin{array}{l}\text { Constativo } \\
\text { Axiologico }\end{array}$ \\
\hline $\begin{array}{l}\text { Fernanda } \\
\text { Tapia }\end{array}$ & 2 & $\begin{array}{l}\text { - Es bastante versatil. } \\
\text { radio. } \\
\text { - Se me hace una persona muy capaz sabe } \\
\text { manejar todo tipo de programas, tiene } \\
\text { mucha cultura. }\end{array}$ & $\begin{array}{l}\text { Axiologico } \\
\text { Constativo } \\
\text { Axiológico }\end{array}$ \\
\hline
\end{tabular}

De estos dos cuadros se podrían proporcionar muchas interpretaciones sobre lo que, de acuerdo a los alumnos, hace que una persona sea un buen o mal comunicador; información que puede ser útil para reconstruir la imagen que tienen los estudiantes sobre el perfil del comunicador. En la expresión de sus opiniones, los alumnos hacen surgir valores que están anclados en ciertos preconstruidos culturales e ideológicos que pueden ayudar a reconstruir la representación social que tienen sobre la labor de un comunicador, cuestión que espero poder presentar en futuros avances de la investigación.

\section{Comentarios finales.}

Para finalizar me gustaría señalar que por limitaciones de espacio no puedo mostrar el tipo de análisis argumentativo que he llevado a cabo; solamente me gustaría recalcar la importancia de este tipo de análisis ya que la actividad discursiva es sin duda la expresión más compleja a la que pueden dar lugar las representaciones sociales. Siguiendo a Grize, podría afirmar que no existe discurso que no sea un poco elaborado y que no presente huellas de argumentación, o como señala Billig, las representaciones sociales están montadas en argumentaciones que afirman y niegan que justifican y critican (Cf. Billig 1988, 1991). Dependiendo del enfoque metodológico que se adopte se puede, entre otras cuestiones, analizar el involucramiento del locutor, la manera en que el sujeto le confiere credibilidad a su discurso, el tipo de citación de fuentes.

Si bien lo que he querido mostrar en este avance de la investigación es el tipo de acercamiento teórico metodológico utilizado, el instrumento diseñado y los diferentes tipos de análisis realizados, algunas conclusiones preliminares podrían extraerse de la información presentada. 
Primeramente, quisiera señalar que si bien las Escuelas de Comunicación, y en este caso la carrera de Comunicación Social de la UAM-X, preparan egresados que se insertarán en campos profesionales más allá de los medios de comunicación, la mayoría de los alumnos entrevistados comparten la imagen de que el campo laboral de los egresados es fundamentalmente el de los medios de comunicación masiva.

La saturación del mercado laboral en los medios es una problemática que tienen que enfrentar los egresados de comunicación. Aunque algunas instituciones educativas alertan a los estudiantes sobre esta problemática (cf. Pérez Isabel, 2003) es interesante observar cómo la representación que tienen sobre el campo laboral de la comunicación social está anclada en ciertos preconstruidos culturales e ideológicos que los llevan a identificar a íus medios de comunicación masiva como el campo laboral en el que creen van a encontrar trabajo. También llama la atención que en relación con la motivación, es decir las razones que expresan para explicar por qué decidieron estudiar comunicación social, los datos obtenidos muestran que un gran número de alumnos (aquí la comparación por trimestres podría ser de gran utilidad), no tienen una motivación muy precisa, cuestión que puede influir altamente en su rendimiento académico.

\section{Bibliografía}

Banchs, Ma. Auxiliadora, "Aproximaciones procesuales y estructurales al estudio de las representaciones sociales", en Papers on Social Representations, Vol. 9, 2000, Electronic Version.

Billig, M., et al. Ideological dilemmas. A social psychology of everyday thinking, London, Sage, 1988. Ideology and opinions. Studies in rhetorical psychology, London, Sage, 1991.

Benassini, Claudia, "El imaginario social del comunicador. Una propuesta de acercamiento teórico" en Razón y Palabra, Primera revista electrónica en América Latina especializada en tópicos de la comunicación, febrero-marzo 2002, ITESM.

Farr, Robert, «Las representaciones Sociales», en Serge Moscovici, Psicología Social II, Paidós, Barcelona, 1986, pp. 495-506.

Grize, J.B.; De la logique a l'argumentation, Genève, Librairie Droz, 1982.

Grize, J-B., Verges, P., Silem, A. Salaires face aux nouvelles technologies. Vers une approche sociologique des 
représentations sociales, Centre National de la Recherche Scientifique, Francia, 1987.

Grize, J.B.; Logique et langage, Paris, Ophrys, 1990.

Gutiérrez, S., «Análisis argumentativo y esquematización», Revista Versión. Estudios de Comunicación y Política, No. 1, octubre 1991, UAM-Xochimilco.

Gutiérrez, S., "Identidad cultural y representaciones sociales", en Anuario de Investigación 1998, Departamento de Educación y Comunicación, UAM-X, México, pp. 43-56.

Ibáñez, Tomás, "Representaciones sociales, teoría y método" en Psicología Social Construccionista, Colección Fin de Milenio, Universidad de Guadalajara, México. 1994, pp. 155-216.

Jodelet, Denise., «La representación social: fenómenos, conceptos y teoría», en Serge Moscovici, Psicolología Social II, Paidós, Barcelona 1986, pp. 469-494.

Martín Serrano, M. "Las clases de mediaciones con las que los medios de comunicación de masas intervienen en la representación del acontecer", en Pérez, Rafael, A. , Estrategias de comunicación, Ariel Comunicación, Barcelona, 2001.

Moscovici, Serge, El psicoanálisis su imagen y su público, Huemul, Buenos Aires, 1979.

La era de las multitudes. Un tratado histórico de psicología de las masas, F.C.E., México, 1982.

Pérez, Isabel, "Ciencias de la comunicación, carrera del espejismo"en Milenio, 28 de enero 2003.

Piñuel, José Luis, "Estrategias de comunicación y representaciones sociales", TELOS, No. 11, Madrid, 1987, pp. 54-11.

"La mediación comunicativa y la construcción de identidades: El nacionalismo en Québec", Reporte de la investigación subsidiada por el International Council for Canadian Studies, 2001, web.jet/piñuel.raigada/indes.html

Ponte, Jorge R., La Fragilidad de la Memoria. Representaciones, prensa y poder en una ciudad latinoamericana en tiempos del modernismo. Mendoza, 1985/1910, Ediciones Fundación CRICYT, Mendoza, 1999.

Rimé, Bernard, "Lenguaje y comunicación", en Serge Moscovici (comp.) Psicología Social II, Paidós, Barcelona, 1986, pp. 535571.

Wolf, Mario, La investigación de la comunicación de masas. Crítica y perspectivas, Paidós, México, 1991. 